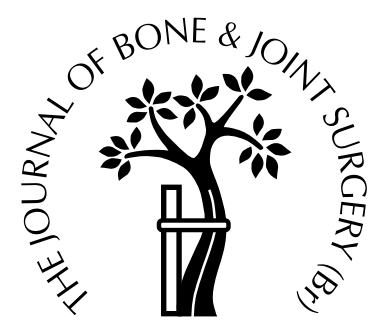

\title{
Friction burns within the tibia during reaming
}

\author{
ARE THEY AFFECTED BY THE USE OF A TOURNIQUET?
}

P. V. Giannoudis, S. Snowden, S. J. Matthews,

S. W. Smye, R. M. Smith

From St James's University Hospital, Leeds, England

$\mathbf{W}$ e have carried out a prospective, randomised trial to measure the rise of temperature during reaming of the tibia before intramedullary nailing. We studied 34 patients with a mean age of 35.1 years (18 to 63) and mean injury severity score of 10 (9 to 13). The patients were randomised into two groups: group 1 included 18 patients whose procedure was undertaken without a tourniquet and group 2, 16 patients in whom a tourniquet was used. The temperature in the bone was measured directly by two thermocouples inserted into the cortical bone near the isthmus of the tibial diaphysis. Reaming was carried out to at least $1.5 \mathrm{~mm}$ above the required diameter of the nail. Blood loss was assessed by recording the preoperative and postoperative haemoglobin $(\mathrm{Hb})$ level.

The minimum clinical follow-up was six months. In group 1 (no tourniquet), the mean $\mathrm{Hb}$ dropped $2.8 \mathrm{~g} / \mathrm{dl}$ from $14.3 \pm 1.02 \mathrm{~g} / \mathrm{dl}$ to $11.5 \pm 1.04 \mathrm{~g} / \mathrm{dl}$ $(p=0.0001)$, whereas with the tourniquet, the mean decrease was $1.3 \mathrm{~g} / \mathrm{dl}$ from $14 \pm 1 \mathrm{~g} / \mathrm{dl}$ to $12.7 \pm 1.3 \mathrm{~g} / \mathrm{dl}$ $(p=0.007)$. This difference was not statistically significant. The mean initial tibial temperature was $35.6^{\circ} \mathrm{C}$ (SD 0.6 ) and rose with reaming to levels between $36.3^{\circ} \mathrm{C}$ and $51.6^{\circ} \mathrm{C}$. The highest temperatures were obtained with the largest reamers (11 and $12 \mathrm{~mm}, \mathrm{p}=0.0001$ ) and the most rapid rise with the smallest diameters of medullary canal (8 or 9 mm). The rise of temperature was transient $(20 \mathrm{~s})$.

We were unable to identify any effect of the use of a tourniquet on the temperature achieved. Reamed intramedullary tibial nailing induces a transient

P. V. Giannoudis, MD, EEC(Orth), Consultant Orthopaedic Surgeon S. J. Matthews, FRCS, Consultant Orthopaedic Surgeon

R. M. Smith MD, FRCS, Professor

Department of Trauma and Orthopaedics

S. Snowden, BSc, Senior Physicist

S. W. Smye, PhD, Director

Department of Medical Physics

St James's University Hospital, Beckett Street, Leeds LS9 7TF, UK.

Correspondence should be sent to Dr P. V. Giannoudis.

(C)2002 British Editorial Society of Bone and Joint Surgery 0301-620X/02/412563\$2.00 elevation of temperature which is directly related to the amount of reaming.

J Bone Joint Surg [Br] 2002;84-B:492-6.

Received 26 June 2001; Accepted after revision 26 October 2001

Intramedullary reaming damages the medullary circulation resulting in reversed blood flow, from centrifugal to centripetal. $^{1,2}$ This change in vascular kinetics, however, is not associated with impairment of bone healing and may actually enhance it. Rises in temperature of more than $50^{\circ} \mathrm{C}$ have been reported ${ }^{3,4}$ during the intramedullary reaming process. These may lead to thermal necrosis of bone altering its endosteal architecture and resulting in biological failure. ${ }^{5}$ Although commonly quoted, clinical evidence of this complication is rare and only seven cases have been reported in the literature. ${ }^{6-8}$ Besides the injudicious use of reaming, the application of a tourniquet has been thought to be a factor in thermal necrosis.

Those who advocate the use of a tourniquet claim that it provides a bloodless field for surgery of the limb. Opponents claim that it prevents transfer of heat by convective blood flow ${ }^{9}$ and is thus a potential risk factor for thermal necrosis. In order to test these arguments we have undertaken a prospective randomised, controlled trial measuring the rise of temperature during reaming of the tibia with and without the use of a tourniquet. We also measured the loss of blood in each case.

\section{Patients and Methods}

Between February 1998 and May 2000, we studied prospectively 34 adult patients who were undergoing a reamed nailing procedure for an isolated fracture of the diaphysis of the tibia. Exclusion criteria were open tibial fractures, acute compartment syndrome and segmental fracture patterns. Approval was obtained from the Research Ethical Committee and all the patients gave verbal or written informed consent before beginning the study. There were 24 men and ten women with a median age of 35.1 years (18 to 63). The median injury severity score (ISS) ${ }^{10}$ was 10 (9 to 13). Road-traffic accidents accounted for 21 of the injuries, sports for seven, and a simple fall for six.

On admission, patients were randomly selected into two 


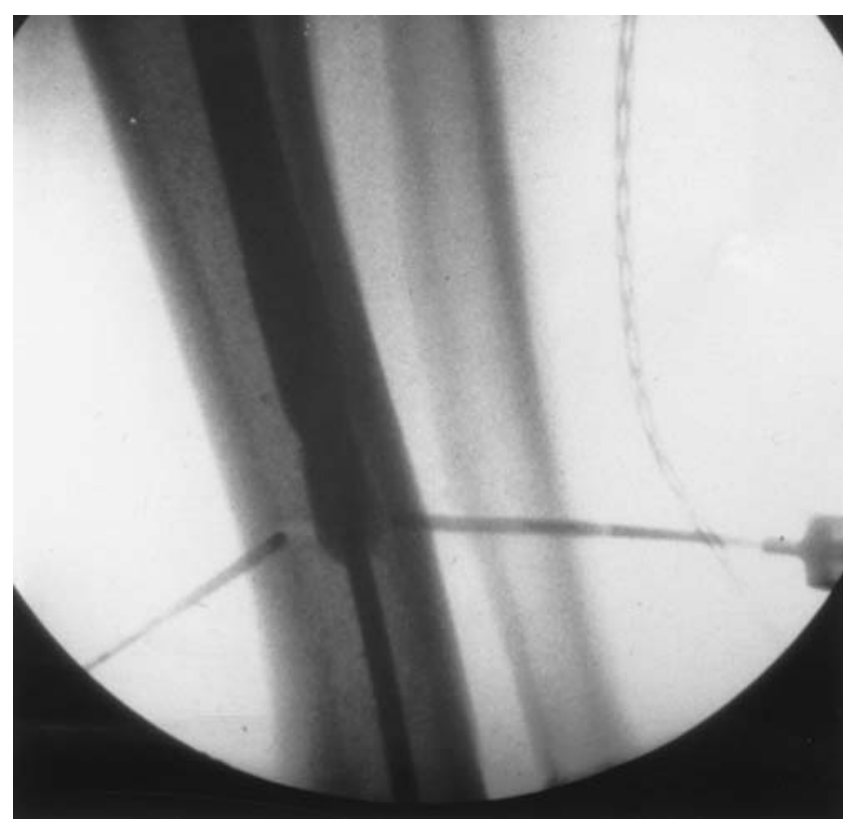

Fig. 1

Two temperature probes inserted into the tibial cortical bone during reaming.

groups by the use of closed envelopes and were assigned to have the fracture stabilised either with or without a tourniquet. Group 1 included 18 patients whose fractures were stabilised without a tourniquet and group 2, 16 patients in whom a tourniquet was used at a pressure of $300 \mathrm{mmHg}$. In each patient, reaming of the medullary cavity was carried out using sharp AO reamers (Synthes, Davos, Switzerland) with the Synthes Air drive operating at 6 bar as is standard procedure. $^{11}$ All operations were undertaken by the senior author (RMS). The canal was reamed to a diameter just sufficient for insertion of the nail. In all except two patients, the minimum reaming was to $1.5 \mathrm{~mm}$ above the required diameter of the nail. The initial diameter of the tibial canal ranged from 8 to $11 \mathrm{~mm}$. The maximum diameter reamed varied between 9 and $12 \mathrm{~mm}$ before insertion of the nail. There was no difference between the two groups with respect to the size of the nail and the extent of reaming.

Intraoperative monitoring of the temperature changes during reaming of the medullary cavity were done by two probes ( $2 \mathrm{~mm}$ diameter, $50 \mathrm{~mm}$ long) inserted into the narrowest part of the cortical bone at the short isthmic segment of the tibial shaft (Fig. 1). The probes were placed in the cortical bone under image intensification so that the distal tip of the probe was approximately $2 \mathrm{~mm}$ from the medullary wall. The temperature probes were of platinum resistance, encased in stainless steel with a silicone rubber cable sheath. Such devices have a response time of about $800 \mathrm{~ms}$ for a step change from $20^{\circ} \mathrm{C}$ to $100^{\circ} \mathrm{C}$ (AJ Thermosensors Ltd, Worthing, UK). The connectors used were Neutrik brand, die-cast zinc (Farnell Electronic Components, Leeds, UK), black chrome plated with glass-re- inforced nylon insulators and gold-plated pins, giving a quoted contact resistance of $3 \mathrm{M} \Omega$. The probe assemblies were gas sterilised. Data were collected by a Tracker 3000 data logger (AJ Thermosensors Ltd). Electrical isolation units (TC1-2/RTI-2) powered by a DIN700 isolated power supply (AJ Thermosensors Ltd) were used between the temperature probes and the data logger, for patient safety. The data logger was supplied precalibrated to a quoted accuracy of $\pm 2^{\circ} \mathrm{C}$ with a stated linearity of $\pm 0.03 \%$. Temperatures were recorded every five seconds and measurements done in duplicate. The entire recording was subsequently uploaded to a personal computer and the data were analysed using a statistical package (Astute, The University of Leeds, UK). The blood loss was assessed by recording the pre- and postoperative haemoglobin $(\mathrm{Hb})$ levels; no perioperative transfusions were given.

The development of soft-tissue thermal necrosis was assessed by daily inspection of the soft-tissue envelope of the tibia. That of aseptic osteonecrosis was assessed indirectly by the progress of union of the fracture with regular radiographs. Any inflammation was documented. The minimum clinical follow-up was six months. No patient was lost to follow-up.

Statistical analysis. Data were expressed as means and standard deviations. Variations with time and differences between trends among groups were assessed by repeated measurements and two-way analysis of variance (ANOVA). Correlations were calculated using the Kendal Rank method. Differences were considered to be statistically significant when $\mathrm{p}<0.05$.

\section{Results}

There were no differences between the two groups of patients in respect of gender, age, ISS or the diameter of the tibial canal $(\mathrm{p}>0.05)$. The mean $\mathrm{Hb}$ level decreased from $14.1 \mathrm{~g} / \mathrm{dl}$ (12 to 16.6$)$ to $12.1 \mathrm{~g} / \mathrm{dl}$ (9.2 to 14$)$ overall. In group 1 (no tourniquet), the mean $\mathrm{Hb}$ fell from $14.3 \pm 1.02 \mathrm{~g} / \mathrm{dl}$ to $11.5 \pm 1.04 \mathrm{~g} / \mathrm{dl}(\mathrm{p}=0.0001)$, whereas with the tourniquet applied, it decreased from $14 \pm 1 \mathrm{~g} / \mathrm{dl}$ to $12.7 \pm 1.3 \mathrm{~g} / \mathrm{dl}(\mathrm{p}=0.007)$. The difference did not reach statistical significance $(\mathrm{p}=0.08)$.

The mean initial tibial temperature before reaming was $35.6^{\circ} \mathrm{C}$ (SD 0.6). During reaming it rose to between $36.3^{\circ} \mathrm{C}$ and $51.6^{\circ} \mathrm{C}$. The highest temperatures were obtained using the largest reamers (11 and $12 \mathrm{~mm}$ ), but occurred in a small number of patients. The most rapid rise occurred with the smallest diameters of the medullary canal $(8$ or $9 \mathrm{~mm})$. The rise of temperature was transient (20s). A direct correlation was noted between the elevation of temperature and the size of the reamer (Kendall Rank, $p=0.0001$, Fig. 2). A higher rise was observed with the use of a tourniquet, but this did not reach statistical significance $(\mathrm{p}=0.09$, AUC, Fig. 3).

There was no intra- or postoperative complication related to infection or thermal necrosis of either skin or bone. All 


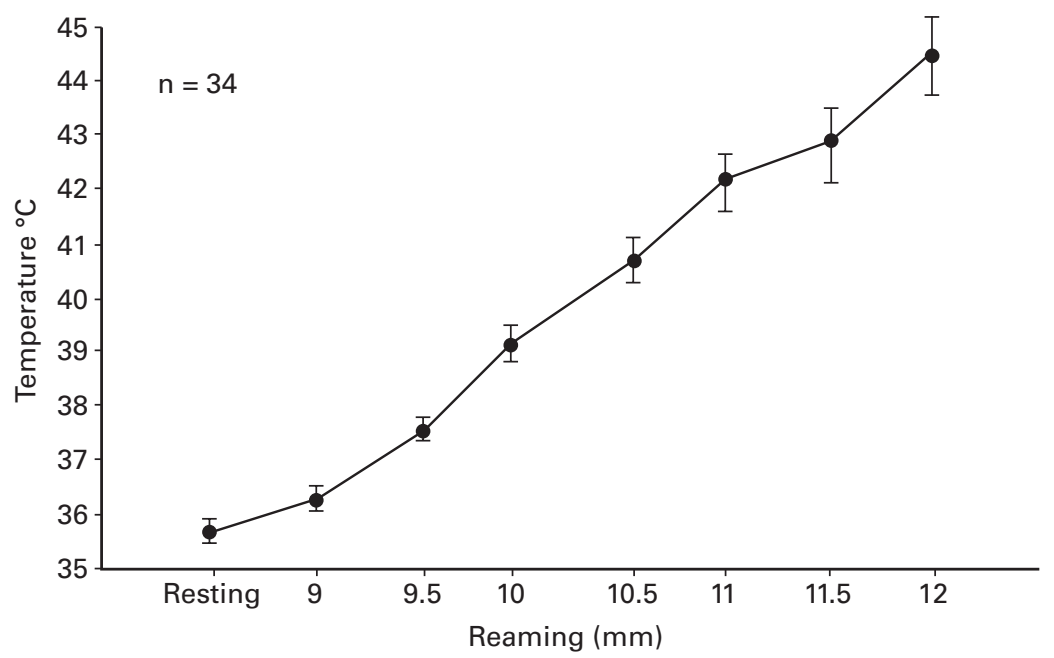

Fig. 2

The rise of temperature compared with the amount of reaming.

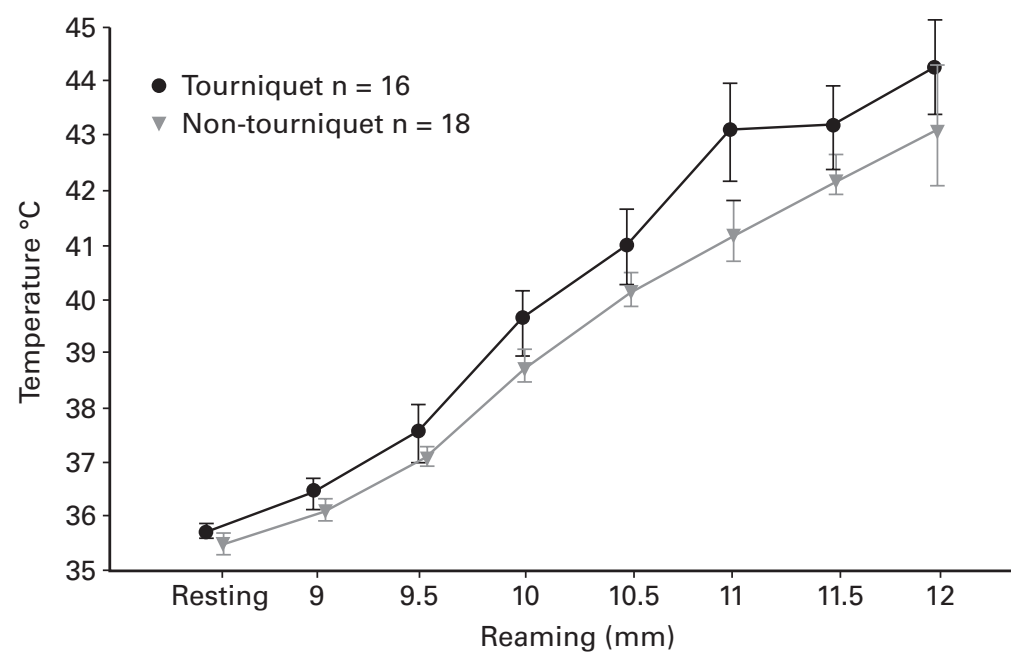

Fig. 3

The rise of temperature with and without a tourniquet.

fractures progressed to union within a mean time of 21 weeks (16 to 26$)$.

\section{Discussion}

Reaming can cause injury to bone as a result of high intramedullary pressures, damage to the endosteal blood supply or the generation of heat. ${ }^{7,12,13}$ When considering the generation of heat, the following questions need to be addressed; what is the temperature threshold above which thermal necrosis occurs, to what extent does the temperature rise during reaming and, most importantly, what is the effect of the tourniquet?

Thermal injury to bone has been reported with temperatures between $43^{\circ}$ and $68^{\circ} \mathrm{C} .^{14,15}$ The critical tem- perature for thermal injury is $56^{\circ} \mathrm{C}$, which is that at which denaturation of alkaline phosphatase occurs. ${ }^{16}$ Extensive cortical necrosis is known to occur at temperatures higher than $70^{\circ} \mathrm{C}$ although the collagen and bone tissue can withstand higher temperatures before denaturation and cellular necrosis take place. ${ }^{17,18}$

Several authors have addressed the second question, regarding the effect of intramedullary reaming on the rise of temperature. Leighton et $\mathrm{al}^{19}$ reamed 11 femora taken from cadavers from which all soft tissue had been stripped, and reported temperatures of up to $44.6^{\circ} \mathrm{C}$. Muller et al, ${ }^{20}$ in an attempt to simulate the biological environment, reamed five pairs of human femora in a water bath at $37^{\circ} \mathrm{C}$ and reported peak values of $44.1^{\circ} \mathrm{C}$ when reaming to $14.5 \mathrm{~mm}^{20}$ Stewart $^{3}$ assessed the elevation of temperature 
during reaming of cadaver bovine metatarsal bones and reported an increase up to $54.5^{\circ} \mathrm{C}$. We present the first study in vivo which reflects physiological conditions. A direct correlation was recorded between the rise of temperature and the amount of reaming. Our findings correlate with those of Ochsner et $\mathrm{al}^{7}$ and of Henry et $\mathrm{al}^{21}$ who also found a correlation between elevation of temperature and size of the reamer. Several co-factors have been considered to affect this elevation during reaming, including the bluntness of the reamers, the speed of the drill and the force applied. ${ }^{20}$ Matthews and Hinsch ${ }^{17}$ investigated the effect of drilling bone and reported that the applied force was more important than the rotational speed. These observations were considered in our study and reaming was carried out carefully and only by one surgeon throughout. Furthermore, the state of the reamers was checked regularly to ensure their sharpness.

Previously cited reports of osteocutaneous necrosis after tibial reaming were associated with a narrow medullary cavity, but suggested that the damage may be attributed to the use of a tourniquet. ${ }^{7,8}$ Theoretically, the use of a tourniquet eliminates convective heat transfer by shutting down the blood flow of the limb. Klenerman and Crawley ${ }^{22}$ reported, in an experimental study, that the circulation was reduced to less than $1 \%$ of that of the control limb. Other authors have reported a varying amount of blood, bypassing the tourniquet and flowing into the distal part of the limb by the way of the medullary canal, measuring as much as $26 \%$ of normal. ${ }^{23,24}$ Despite the wide variations which have been reported, there is no doubt that a tourniquet may interfere with the dissipation of heat through the circulation. This effect has been demonstrated in studies on thermal conductivity in which a fourfold difference between dry and living bone tissue has been reported. ${ }^{9}$ In our study the rise of temperature in the group of patients with a tourniquet appeared to be slightly higher, but this difference did not reach statistical significance. This finding is open to a number of interpretations. First, the heat produced flows both into the bone and into the reamer. This process may be described by the heat-conduction equation, with appropriate values for critical parameters, including rotational speed, the dynamic friction coefficient, the cavity and dimension of the reamer and thermal conductivities. It is therefore obvious that changes in thermal conductivities only may not be sufficient to induce substantial elevations of temperature during reaming. Secondly, according to the study protocol, the minimum reaming was at least $1.5 \mathrm{~mm}$ above the required diameter of the nail. Clearly, more reaming would have led to higher temperatures. Excessive reaming of the medullary cavity was advocated in the past for the insertion of nails of large diameter thus exposing the patient to the risk of damaging thermal energy. The development of a new generation of intramedullary implants, which are thinner but not weaker, has resolved this problem but we felt that the real clinical situation should be assessed. Thirdly, the cooling effect exerted by the cortical blood flow may have been overestimated. During reaming, vascular occlusion and damage occur rapidly and may interfere with convection cooling. Matthews and Hinsch ${ }^{17}$ comparing in vivo and in vitro heating curves during drilling, reported no significant effect from vascular cooling. Finally, the small number of patients recruited in this study may raise the possibility of a type-II statistical error. A power calculation revealed that 73 patients would be required for significance.

In practice, it is not possible to assess directly the impact of high temperature on bone (thermal necrosis) since this would require tissue biopsies. For that reason the thermal effect on the tissues was assessed by the daily inspection of the tibial soft-tissue envelope and the progress to bony union. While we accept that visual inspection of the soft tissues may not be a reliable indication of the extent of thermal damage, none of the patients had intra- or postoperative signs of inflammation or blisters or necrosis on the skin. All patients achieved bony union uneventfully which suggests no adverse effect.

The mean Hb level, with and without the use of tourniquet, decreased noticably; the difference, however, between the two groups of patients did not reach statistical significance.

In conclusion, it appears that reaming induces a transient generation of temperature in the tibia. This heating effect is proportional to the amount of reaming of cortical bone. The application of a tourniquet and reaming to $1.5 \mathrm{~mm}$ above the required diameter of the nail appear to be safe clinical practice.

No benefits in any form have been received or will be received from a commercial party related directly or indirectly to the subject of this article.

\section{References}

1. Klein MPM, Rahn BA, Frigg R, et al. Reaming versus non-reaming in medullary nailing: interference with cortical circulation of the canine tibia. Arch Orthop Trauma Surg 1990;109:314-6.

2. Schemitsch EH, Kowalski MJ, Swiontkowski MF, Harrington RM. Comparison of the effect of reamed and unreamed locked intramedullary nail on blood flow in the callous and strength of union following fracture of the sheep tibia. $J$ Orthop Res 1995;13:382-9.

3. Stewart R. Temperature elevation in cortical bone during intramedullary reaming and the effect of intermittent IM irrigation and sharp reamers. Procs Orthopaedic Trauma Association 1998:265-6.

4. Baumgart F, Kohler G, Ochsner PE. The physics of heat generation during reaming of the medullary cavity. Injury 1998;29,Suppl 2:11-25.

5. Rhinlander FW. The normal microcirculation of diaphyseal cortex and its response to fracture. J Bone Joint Surg [Am] 1968;50-A:784800.

6. Povacz F. Thermal damage to the tibial diaphysis caused by intramedullary reaming. Unfallheilkunde 1979;82:126-8.

7. Ochsner PE, Baumgart F, Kohler G. Heat-induced segmental necrosis after reaming of one humeral and two tibial fractures with a narrow medullary canal. Injury 1998;29,Suppl 2:1-10.

8. Leuning M, Hertel R. Thermal necrosis after tibial reaming for intramedullary nail fixation: a report of three cases. J Bone Joint Surg [Br] 1996;78-B:584-7.

9. Sundén G. Some aspects of longitudinal bone growth: an experimental study of the rabbit tibia. Acta Orthop Scand 1967;Suppl 103. 
10. Baker SP, O'Neill B, Haddon W, Long WB. The injury severity score: a method for describing patients with multiple injuries and evaluating emergency care. J Trauma 1974;14:187-96.

11. Synthes. Original instruments and implants of the Association for the Study of Internal Fixation. Stratec Medical, Switzerland, 1998:562-5.

12. Danckwardt-Lilliestrom G. Reaming of the medullary cavity and its effect on diaphyseal bone. Acta Orthop Scand 1969;128,Supp:14550.

13. Larsen RM. Intramedullary pressure with particular reference to massive diaphyseal bone necrosis: experimental observations. Ann Surg 1938;108:127-40.

14. Thompson HC. Effect of drilling into bone. J Oral Surg 1958;16:22-5.

15. Pallan FG. Histological changes in bone after insertion of skeletal fixation pins. J Oral Surg 1960;18:400-8.

16. Flory PJ, Garrett RR. Phase transitions in collagen and gelatin systems. J Am Chem Soc 1958;80:4836-41.

17. Matthews LS, Hinsch C. Temperatures measured in human cortical bone when drilling. J Bone Joint Surg [Am] 1972;54-A:297308.
18. Berman AT, Reid JS, Yanicko DR, et al. Thermally induced bone necrosis in rabbits: relation to implant failure in humans. Clin Orthop 1984;186:284-92.

19. Leighton RK, Alzahrani A, Sahajpal D, Smyth B, Petrie D. A comparison of the intramedullary pressures and temperatures generated during reaming between the standard reaming system and a new low pressure designed reaming system. Procs Orthopaedic Trauma Association 1998:217-8.

20. Muller C, McIff T, Rahn BA, Pfister U, Weller S. Intramedullary pressure, strain on the diaphysis and increase in cortical temperature when reaming the femoral medullary cavity: a comparison of blunt and sharp reamers. Injury 1993;24,Suppl 3:22-30.

21. Henry SL, Adcock RA, Von Fraunhofer JA, Seligson D. Heat of intramedullary reaming. South Med J 1987;80:173-6.

22. Klenerman L, Crawley J. Limb blood flow in the presence of a tourniquet. Acta Orthop Scand 1997;48:291-5.

23. Spira E, Katznelson A, Czerniak P, Mikolajkow A. Osseous blood circulation in the lower limb: animal and clinical experiments. Isr J Med Sci 1965;1:573-8.

24. Furlow LT. Cause and prevention of tourniquet ooze. Surg Gynecol Obstet 1971;132:1069-72. 